\title{
The Restructuring of Broadcasting Methods and Preferences during the North African Insurgencies of 2011: How Social Media Redefined Journalism and the Wider Media in Egypt and Tunisia During the Arab Uprisings of 2011
}

\author{
By Ayman Alrehaili*
}

\begin{abstract}
The revolutions in Egypt and Tunisia during 2011 brought about vast political upheaval. Moreover, these insurrections redefined journalism and media usage. At the heart of this transformation were the social media websites Facebook, Twitter and Blogger. This study will explore the role social media played in changing the traditional media during this tumultuous period, notably determining how news dissemination evolves during periods of dramatic political change. The popular narratives that expounded the importance of social media, plus the empirical studies that questioned its impact will be examined. The extent of the influence social media had on the revolutions will also be discussed. The research is based on twelve detailed, qualitative interviews which were collected with journalists working in Egypt and Tunisia and elsewhere in the Middle East during the period studied. The interview data will reveal the processes by which social media has overhauled journalistic practices, particularly broadcasting, in Egypt and Tunisia. The implications of this research is to show how the process by which social media transforms traditional journalistic practices was accelerated by the uprisings experienced in Egypt and Tunisia after 2011. This supports my stated theory that social media can transform traditional journalistic practices when journalists at established media outlets are exposed to the medium, a view outlined through the literature reviewed.
\end{abstract}

Keywords: Arab uprising, social media, traditional media, censorship

\section{Introduction}

The aim of this research is to explore the role social media played in changing traditional media during this tumultuous period, notably demonstrating how news dissemination evolves during periods of dramatic political change. The present research fills a gap in the existing studies around this topic insomuch as it does not focus solely on the role social media played in the uprisings across the Middle East in 2011; instead it looks at the impact of both social media and the uprisings, in combination, on traditional journalistic practices and media structures. This is an area few researchers had explored before I undertook my study.

While commanding regimes in Tunisia, Egypt, and elsewhere in the Middle East may have broadly succeeded in their attempts to censor traditional forms of media, the advent of widespread internet usage across the region presented these authorities with a whole new challenge.

${ }^{*}$ PhD Student, Nottingham Trent University, UK. 
Before considering this dilemma and its management, it is worth noting that the Middle East experiences a greatly reduced Internet penetration, as compared to Europe, North America and East Asia, thus traditional forms of media censorship remained attainable and practical for longer than they would have in other parts of the world. El Gody (2007) notes that, "the Arab world is generally known as a laggard in adopting and utilizing new technologies and the Internet is no exception." But while the region was a late adopter, once it finally did begin implementing online technologies, the Middle East embraced the internet revolution with such enthusiasm that in the last decade, the growth in Internet penetration has been faster in this region than anywhere else on earth - a staggering 1,825\% rise in usage in the last ten years, versus $432 \%$ growth around the rest of the world in the same period (Internet World Stats, 2012). Indeed, by June 2012, Internet availability in the Middle East was above the world average, at $40.2 \%$ versus $34.3 \%$ globally. It is surely no coincidence that this rapid growth in Internet penetration immediately preceded the Arab uprisings of 2011, this question will be addressed in greater detail in a later section.

The speed and timely emergence of the rapid Internet proliferation phenomenon across the region, has produced two primary outcomes. Firstly, that North African government's intent on censoring media outlets only began to feel threatened by the Internet as an instrument with the potential to damage this established protocol, towards the middle of the last decade. And secondly, when these governments ultimately accepted that the Internet could be a threat to media control, they had very little time to respond. Early, crude, attempts to control Internet content, lay in stark contrast with the more sophisticated techniques for censoring film described by Beshir (2013). In their 2003 report, Kalathil and Boas argue that the contradiction between a closed regime and the fundamentally open system that is the Internet meant that the two would not be able to operate alongside each other. Accordingly, the liberal, all-inclusive nature of the Internet makes it incompatible with closed, autocratic regimes, thus when the two are juxtaposed, one or the other will become fundamentally reorganised. Either the government will be coerced into more candid communication, or the Internet in that region will become heavily censored. The latter has broadly been the case too with authoritarian governments in the Middle East. The Internet though, was barely a concern for these governments when Kalathil and Boas wrote their report in 2003. They highlight the contradiction at the heart of this issue. The Internet, they assert, is fundamentally an open system, thus was considered extremely dangerous by the totalitarian administrations of Tunisia and Egypt pre-2011.

\section{Literature Review}

In this section, we shall examine the popular narratives expounded on the importance of social media in Egypt and Tunisia during this period. The extent of the influence social media had on the revolutions will also be discussed 
within the context of how it may have accelerated the process by which traditional journalistic practices were transformed and shaped during this period.

While Arab governments tended to see the Internet and connected technologies as a new voice for their propaganda, millions of users have accessed it as a new method to consume uncensored, international news, or to express views that had no outlet during the days of stricter, unchallenged censorship. Prior to 2011, it was certainly the case that both Egypt and Tunisia heavily censored the Internet during a period where more and more people were gaining access to it for the first time. In 2009, both countries were included in a list of twelve "Enemies of the Internet" in a report by Reporters without Borders (2009). The report stated that both countries had, "turned their net into an Intranet, thus preventing users from accessing information that their governments regarded as undesirable". Both of these nations clearly demonstrated, not only their ability to censor information, but also how they systematically repressed trouble-making cybernauts.

The level of censorship in Tunisia and Egypt differs significantly prior to 2011. Tunisia's censoring entails "pervasive filtering" of political and social content on the Internet. The censorship was predicated upon a surge in Internet usage in the country, with a 2009 OpenNet Initiative report noting that, "Tunisia has one of the most developed telecommunications infrastructures in North Africa with a high mobile penetration rate and one of the lowest broadband prices in Africa." Importantly, Internet access had become so pervasive in Tunisia that many were accessing the Internet via mobile devices, "It was against this background that the Tunisian government deemed it necessary to censor the Internet to maintain political control." As well as filtering, "the government of Tunisia utilizes laws, regulations and surveillance to achieve strict control over the Internet" (OpenNet Initiative, 2009). This surveillance led to a number of notable convictions, including that of Mohamed Abbouin 2005, for publishing a report accusing the Tunisian government of torturing prisoners. The situation was somewhat better in Egypt pre-2011. OpenNet's 2009 report on the country found "no evidence of political or social Internet filtering in Egypt," but it does state that "a small group of politically sensitive Web sites have been blocked in the past." Furthermore, the authorities have increased their severe measures to discourage online dissenter's writers and bloggers and some have been harassed or detained for their activities. Like Tunisia, Egypt's Internet presence is among the highest in North Africa, "with an Internet penetration rate of $15.4 \%$, Egypt is ahead of most of Africa, though it lags behind many Middle Eastern countries such as the UAE and Qatar. It is important to recognise the different approaches undertaken by Egypt and Tunisia prior to 2011, in relation to Internet censorship, especially given the similarities in Internet penetration and the ways each government censored other forms of media. While Tunisia was more active in censoring and filtering the Internet, in Egypt, Hosni Mubarak president of Egypt was happy to allow the Internet to, on the whole, develop unchecked. This was during a period when, "the number of blogs in Egypt rose from just 40 in 2004 to an estimated 
160,000 in July 2008 (OpenNet Initiative, 2009). The Internet was not a wholly safe place for activists in Egypt, and was severely limited for those in Tunisia. It was against this backdrop that the Arab demonstrations of 2011 took place and as will be revealed later in this research, these factors played a significant role in transforming the media environments within these two countries as a whole.

\section{The Role of Social Media}

Philip Seib (2008) asserts, "To varying degrees throughout the world, the connectivity of new media is superseding the traditional political connections that have brought identity and structure to global politics." This notion has become central to the utopian narrative of social media as a force for political good. But to what extent does this concept hold up under scrutiny? Is there a veiled agenda behind this hypothesis and is it in fact possible that the impact of social media on the Arab uprisings of 2011, was actually negligible? In many respects, it is quite patent that traditional politics have broadly remained the same, even as the forces of globalization and connectivity have become more significant. Seib's principal ideology is constructed on the assumption the Internet will transform the manner in which inhabitants view their own countries and the rest of the world, however this concept and assertion is not substantiated with verified evidence.

At this stage it is important to draw a distinction between the popular narratives that emerged during this period and the serious academic research conducted on the issue. This distinction is important because both schools viewed the process differently and it could be argued that the popular narrative fuelled the process itself. This is not to say that both are not of interest to this research project. This is certainly a point worthy of emphasis: once the populace began to believe that social media could become a vehicle for social and political change, that view became a self-fulfilling prophecy. A major part of this process was expedited by the establishment of a popular narrative, developed both online via the blogs and social media of the Middle East and also through more traditional media outlets across the world. As such, it is the objective of this paper to analyse the significance of social media, firstly through the available academic research and secondly through the populist, contemporary sources that helped develop this narrative.

\section{Literature Review: Media}

Malcolm Gladwell, whose article, Small Change: Why the revolution will not be tweeted, (2010) partly inspired the title of this research, selected the worst possible time to publish a lengthy polemic arguing that social media was unable to harness expressed political dissent and transform it into a real-life protest. The article was published in October 2010, just weeks before the 
beginning of the Arab uprisings. Accordingly, it ran in direct opposition to the fast emerging zeitgeist that would go on to dominate much of the discussion involving the social media's role in the protests, namely, that such demonstrations were inspired by posts on the pages of Twitter, Facebook and Blogger.

This account firstly emerged in the weeks after the earliest protests in Tunisia and Egypt. Indeed by February 25, just two months after the selfimmolation of Mohamed Bouazizi (which is generally accepted to have been the start of the protests), the supposition became so established that some were beginning to explore it further. "Recent events in Libya, Tunisia and Egypt have been called 'Twitter revolutions' but can social networking overthrow a government?" asked one Guardian journalist discussing the protests. He concludes, "... social media has played a role. For those of us who have covered these events, it has been unavoidable" (Beaumont, 2011) and supports his stance with a number of case studies, including statements from Tunisian protesters describing how they utilised social media to organise protests.

It is a similar story from many of the foreign journalists who were investigating the breaking story during the early days and weeks of the Arab uprisings, particularly in Tunisia and Egypt, although generally to a lesser extent in Libya. Note this account from Paul Mason, the BBC correspondent who witnessed many of the protests first hand, "Digital communications and social networks are the two big things facilitating revolutions .... People starting these revolutions are often insulted by suggestions that Facebook and Twitter have anything to do with it, but they do." Mason supports this declaration with an example, "New media are obviously important in circumventing police repression and armed activity. In the early stages of the Egyptian protests, small groups were able to bring out tens of thousands of poor people who cannot read by organising groups of up to five people to go to the same place using texts and social media."

What do Beaumont (2011) and Masons' assertions reveal? On the one hand, it seems contemptuous to instantly dismiss their conclusions, especially as the interpretations are based on a direct observation of the early weeks of the protests. However, on the other hand, it is also prudent to consider their position and motivations. This refers particularly to the propensity to comment on the Arab uprising, describing it in terms of a simple cause-effect metric that would be familiar to the targeted Western audience. The social media narrative, it could be argued, is an attempt to assign the multi-faceted reasoning behind the protests with a framework that would be palatable to a Western audience. It is perhaps no coincidence that the Arab uprisings occurred at precisely the same time that Twitter began to gain a wider usage in the Western hemisphere. Could it be that Mason and Beaumont, both of whom run active accounts on Twitter, were keen to assign the social network a disproportionately important role in the events they had witnessed? There are potentially other Meta considerations. Twitter and Facebook are both popular social networking tools and equally functional in the distribution of news articles. So it is possible that those articles championing the role of social networks in the protests would 
gain wider traction simply because they were more likely to be shared and read by more users. Journalists such as Beaumont and Mason used social networks such as Twitter to increase the exposure of their commentaries. Mason notes, "One of the brilliant things about Twitter is that it kills propaganda. When the Bahrain crackdown began, for example, I happened to be awake and following Twitter. People were saying they are firing live bullets. We tried to check this, and one of the most immediate ways was to follow links to pictures posted from cell phones." Could this popular account simply be the result of a selfreferential loop, of journalists dazzled by social media, using it to report on the conflict and accordingly assigning it too significant a role in the protests?

\section{Theoretical Framework}

The theoretical approach for this research project will be to examine how results from a set of qualitative interviews with journalists who worked in Egypt and Tunisia during the 2011 uprisings fit within a broader framework of literature and theories outlined earlier in this section on how the evolution of social media can transform wider media practices. This theory draws upon broader theories of the media from the likes of Chomsky, which relate to the nature of media under authoritarian control, and Habermas, in terms of how the public sphere can transform civil society.

\section{Method}

The study, conducted in Egypt and Tunisia during the first months of 2014, utilised forty two detailed, qualitative, semi-structured interviews with journalists and social media users, particularly those involved in the protests. It was intended that the qualitative interview would foster and establish a more open ambience, where respondents may feel encouraged to discuss certain subjects in depth, with a greater degree of honesty, without being constrained by specific subject matters or a fixed order of questioning. The semi-structured format was chosen to motivate and stimulate the interviewees, encouraging them to divulge and expand their experiences where relevant, while maintaining a coherent structure.

Sampling. A purposive sample of forty two people was devised via snowball sampling. This was achieved via professional contacts from my own experience working in media in the Middle East. The interviewees were selected based on their experience of working in the media sector in Egypt and Tunisia during this period, and for their knowledge of Middle Eastern media practices.

Data analysis. The qualitative data was analysed using a thematic analytical approach. This entailed analysing transcriptions of interviews conducted with interviewees and drawing out themes from the results, and then analysing these themes within the context of the other interviews and broader 
literature. Several core themes emerged, notably that social media played a major role in the broader media landscape during the Arab uprisings of 2011 in Egypt and Tunisia, that the greater exposure to social media on both journalists and media consumers changed wider journalistic practices, that the advent of widespread social media usage accelerated the process of media transformation in Egypt and Tunisia, and that, broadly speaking, journalists in both these countries embraced the opportunities presented by social media.

\section{Discussion Analysis}

From these interviews a series of broad conclusions that supported the framework developed in my critical review of literature, was made.

Traditional media's role in the uprisings. The demonstrators agreed that traditional media in Egypt was a contributing factor to the dissatisfaction with the wider political situation which led to the protests and ultimately the overthrown government. Indeed, some speculate that if the government had offered Egyptians a freer media earlier, the uprisings may not have gathered as much pace as they did.

That following the revolution, the political polarization of the country left the media, both traditional and alternative, in a difficult and sometime contradictory position. Traditional media tended to return to a safe, pre-2011 ground. But a culture of free expression led to several on-air clashes between the presenters. The state media, on the whole, returned to its previous role of promoting the interests of the ruling regime, despite this regime having changed.

The role of the authoritarian rule in attitudes towards the media. Media professionals and journalists were sometimes harshly treated by the demonstrators, who considered those who had worked for pro-government media to have betrayed their country. There were cases of journalists being assaulted by protesters. The privately owned media was forced to tread carefully when it came to declaring loyalties. Alternative media was not only distinguished from traditional media through the digital medium, but also through a culture of interaction and participation with the audience.

How social media impacted journalistic practices. Social media served an important role in advocating for the Egyptian revolution, particularly through the use of sites such as Facebook which were used not only as a source of news for more demonstrators but also as a means of communication and debate for those keen to exchanging ideas.

Several journalists I spoke to in Egypt said they turned to social media as a source for news during the uprisings. This was because many stories first broke on social media, even if this was in a partially formed nature where the full story was yet to be developed. Nonetheless, it was certainly an important source of information. The traditional media made use of many sources and 
forms, including videos filmed directly from the protests and uploaded to websites such as Youtube.

Shabib notes an incident of harassment during the inauguration of President Sisi as an example of when social media served as a source of a story for traditional journalists. Jamal, however, urged caution in this approach, noting that if journalists did not take time to verify their sources, they could end up broadcasting or publishing news which could not be backed up with facts or sources. He used the example of the Facebook page of the National Alliance, which published updates on the political position of Morsi before he was ousted. The page became a primary source for journalists, but its pronouncements were not always treated with enough journalistic vigour. It is clear that within months of the uprisings, it had become a standard journalistic practice to look towards social media as a source of news from all sides of the dispute.

\section{Conclusion}

It is important, to contextualise the impact social media had during the Arab uprisings with a theoretical model of media evolution within autocratic governments. Without such a context, it is difficult to reach a firm conclusion on the nature of its role in Egypt and Tunisia post-2011.

The primary research revealed that traditional journalism, and the practitioners of journalism within traditional outlets, quickly adopted social media practices during the months following the uprisings in Egypt and Tunisia. The rate of adoption was, within reasonable doubt, accelerated by the political crisis. Indeed, without the political upheaval experienced within these countries post-2011, it could be reasonably assumed that traditional media outlets in these countries would not have committed to such a widespread adoption of new, alternative and social media practices within their reporting.

From this study I would recommend that further work is done to identify how the Middle East's media landscape is evolving. I would also urge that those who conduct this research are not restricted by the traditional frameworks which have tracked the evolution of the Western media in the light of the emergence of social media. Against the backdrop of authoritarian rule, major political protests and a previously highly-censored media, it is clear the Middle East underwent a unique process. However, this process might have wider applications in the future in regions and countries where similar conditions apply. 


\section{Appendix}

\section{The interview subjects are:}

Amr Gamal: Egyptian journalist who has worked for BBC Arabic, Alarab TV and DW TV. He was working in Tunisia and Egypt during the uprisings.

Mohammed Shabeb: Egyptian journalist working for BBC Arabic.

Marwa Raslan: Egyptian journalist working for an Egyptian newspaper.

Fatima Khair: Egyptian journalist and social media user.

Sherif Younis: Egyptian journalist and social media user.

Amr Kenawy: Egyptian journalist and blogger.

Rim Saoudi: Tunisian journalist.

Amal Samet: Tunisian journalist.

Marwa Rekik:Tunisian journalist.

Samira Soury: Tunisian journalist.

Hifa Hamed: Tunisian journalist.

Khawla Chabbeh: Tunisian journalist.

Bghouri Neji: Tunisian journalist and Chairman of the Tunisian Journalists' Syndicate.

\section{References}

Beaumont, P. (2011). The truth about Twitter, Facebook and the uprisings in the Arab world. The Guardian. Retrieved from http://goo.gl/4OjlA. [Accessed: 8 February 2013]

Beshir, M. (2013, March 21). This week in 1937: Egypt's censors ban their first film. Egypt Independent. Retrieved from http://goo.gl/yvhRXO. [Accessed: 4 April 2013]

Mason, P. (2012). The revolution will be tweeted. The New Scientist. Retrieved from http://goo.gl/yp9cN. [Accessed: 9 February 2013]

El Gody, A. (2007) New Media, New Audience, New Topics, and New Forms of Censorship in the Middle East. In: Seib, P. (ed.) New Media and the New Middle East. New York, Palgrave MacMillan. p. 217.

Enemies of the Internet 2014: entities at the heart of censorship and surveillance. (2014, March 11). Report without Borders. Retrieved from: https://goo.gl/DZ Q4Ib. [Accessed: 9 May 2013]

Gladwell, M. (2010, October 4). Why the revolution will not be tweeted." The New Yorker. Retrieved from http://goo.gl/O4Mqsm. [Accessed: 22 January 2013]

Internet World Stats. (2012). Retrieved from http://goo.gl/LpcI. [Accessed: 4 April 2013]

Kalathil, S., \& Boas, T. C. (2003). Open Networks, Closed Regimes: The Impact of Internet on Authoritarian Rule. Washington Carnegie Endowment for International Peace. pp. 22-41.

OpenNet Initiative. (2009). Internet Filtering in Tunisia. Retrieved from https://goo. gl/gGbcGS. [Accessed: 17 April 2013]

Seib, P. (2008). The Al Jazeera Effect: How the New Global Media Are Reshaping World Politics. Potomac Books, location 3028. 
